Т.Ю.Салина, Т.И.Морозова

Продукция фактора некроза опухоли- $\alpha$ мононуклеарными клетками крови при разных клинических вариантах саркоидоза

ГБОУ ВПО "Саратовский государственный медицинский университет им. В.И.Разумовского": 410012, Саратов, ул. Б. Казачья, 112

\author{
T.Yu.Salina, T.I.Morozova
}

\title{
Tumor necrosis factor- $\alpha$ production by blood mononuclear cells in different manifestations of sarcoidosis
}

\begin{abstract}
Summary
Tumor necrosis factor- $\alpha(\mathrm{TNF}-\alpha)$ is a polypeptide mediator and proinflammatory cytokine that plays an important role for pathogenesis of sarcoidosis. The aim of this study was to investigate spontaneous and induced by M.bovis antigen (BCG) and mitogen concanavalin (Con A) production of TNF- $\alpha$ by peripheral blood mononuclear cells in patients with different manifestations of sarcoidosis. The study involved 22 patients with active sarcoidosis of intrathoracic lymph nodes and lungs. TNF- $\alpha$ production was studied in supernatants of blood mononuclear cell cultures using sandwich method and immunoenzyme analysis (ELISE). We found a significant increase in spontaneous and induced TNF- $\alpha$ production in patients with acute sarcoidosis compared to asymptomatic patients and with healthy volunteers. TNF- $\alpha$ hyperproduction induced by non-specific mitogen Con A was also revealed in all sarcoidosis patients regardless of activity of the disease in comparison with healthy controls. These data may indicate an increased functional activity of the immune cells and their tendency to hyperreactivity in response to antigen in patients with sarcoidosis.

Key words: sarcoidosis, tumor necrosis factor- $\alpha$, blood mononuclear cells.
\end{abstract}

\section{Резюме}

Фактор некроза опухоли (TNF- $\alpha$ ) - полипептидный медиатор и провоспалительный цитокин, играющий важную роль в патогенезе саркоидоза. Целью исследования было изучение спонтанной и индуцированной антигеном Mycobacterium bovis (БЦЖ) и митогеном конканавалином (KOH А) продукцию TNF- $\alpha$ периферическими мононуклеарными клетками крови у больных с разными клиническими проявлениями саркоидоза. Были обследованы 22 больных активным саркоидозом внутригрудных лимфатических узлов и легких. Методом иммуноферментного анализа в супернатантах 24-часовых культур периферических мононуклеарных клеток определяли уровень спонтанной и индуцированной БЦЖ и КОН А продукции TNF- $\alpha$. Установлено достоверное усиление спонтанной и индуцированной БЦЖ продукции TNF- $\alpha$ у больных с острыми проявлениями саркоидоза по сравнению с пациентами с бессимптомным течением заболевания и здоровыми. Выявлена гиперпродукция TNF- $\alpha$, индуцированная неспецифическим митогеном КОН А у больных саркоидозом, независимо от клинических признаков активности процесса, в сравнении со здоровыми, что может указывать на повышение функциональной активности иммунокомпетентных клеток у больных саркоидозом и их склонность к гиперреактивности при встрече с антигеном. Ключевые слова: саркоидоз, фактор некроза опухоли- $\alpha$, мононуклеарные клетки крови.

Фактор некроза опухоли- $\alpha$ (TNF- $\alpha)$ - полипептидный медиатор и цитокин иммунного ответа, играющий важную роль в патогенезе и поддержании гомеостаза при гранулематозных заболеваниях $[1-3,5,7]$. Он принимает активное участие в развитии иммунного ответа как кофактор ростовых цитокинов, обусловливает пролиферацию и кооперацию Т и В-лимфоцитов, активирует макрофаги [3], индуцирует освобождение интерлейкина-1 (IL-1) [2], оказывает регуляторный эффект на активность фибробластов, усиливает миграцию иммунокомпетентных клеток в очаг воспаления [3]. TNF- $\alpha$ является ключевым медиатором, участвующим в формировании гранулемы при саркоидозе [2, 8]. В то же время он является мощным провоспалительным цитокином, с избыточной продукцией которого связывают такие клинические симптомы развития заболевания, как лихорадка, потеря массы тела, продукция острофазных белков [9], формирование узловатой эритемы [10].
Некоторыми научными исследованиями была констатирована корреляция между клинической активностью саркоидоза и уровнем IL-1, 4, 6, TNF- $\alpha$ сыворотки крови и бронхоальвеолярной лаважной жидкости [8, 11]. Изложенное позволяет предполагать, что уровень TNF- $\alpha$ может отражать активность одной из начальных фаз иммунологического ответа при саркоидозе [7].

Целью работы являлось изучение спонтанной и индуцированной антигеном Mycobacterium bovis (БЦЖ) и митогеном конканавалином А (KOH А) продукции TNF- $\alpha$ периферическими мононуклеарными клетками крови у больных с разными клиническими проявлениями саркоидоза.

\section{Материалы и методы}

Были обследованы 22 больных саркоидозом (10 мужчин, 12 женщин) в возрасте от 21 до 82 лет (средний 
возраст $-41,4 \pm 2,4$ года) и 15 здоровых лиц. Среди обследованных пациентов саркоидоз внутригрудных лимфатических узлов (ВГЛУ) установлен у 10 (45,6\%) пациентов, саркоидоз ВГЛУ и легких - у $2(9,1 \%)$, изолированный саркоидоз легких без поражения ВГЛУ - у 6 (27,3 \%), саркоидоз ВГЛУ и легких в сочетании с внелегочными поражениями (кожи, бронхов) - у 4 (18,2\%) больных. У $10(45,6 \%)$ пациентов при обследовании выявлены клинические признаки активности процесса, характеризующиеся неспецифическими признаками воспаления (интермиттирующая субфебрильная температура, слабость, артралгии, узловатая эритема, гематологические изменения в виде умеренного лейкоцитоза, ускорения скорости оседания эритроцитов - СОЭ и т. п.). У всех пациентов диагноз верифицирован на основании клиникорентгенологических данных, включая компьютерную томографию высокого разрешения, данные бронхологических и инструментальных методов исследования и морфологическое подтверждение диагноза. В зависимости от клинических проявлений саркоидоза пациенты были распределены в 2 группы: 1 -я $(n=10)$ - больные саркоидозом, имеющие острое течение процесса с высокой активностью воспалительного процесса (лихорадка, артралгии, узловатая эритема, высокая СОЭ); 2-я ( $n=12)$ - больные саркоидозом, у которых отмечалось бессимптомное течение заболевания, изменения в легких были выявлены при профилактическом флюорографическом обследовании; группа контроля $(n=15)$ - здоровые туберкулинположительные лица.

У всех больных проводили определение спонтанной и индуцированной Mycobacterium bovis (БЦЖ) и КОН А продукции ТNF- $\alpha$ in vitro в супернатантах 24-часовых культур периферических мононуклеарных клеток, выделенных из периферической венозной крови на градиенте плотности фиколл-урографин ( $p=1,114$ г / см при 200 г). Мононуклеарные клетки культивировали в среде RPMI (Flow Laboratories Ltd, Великобритания), содержащей $10 \%$ инактивированной нагреванием эмбриональной телячьей сыворотки, 2 мМ глютамина и по 100 ед. / мл пенициллина и стрептомицина при $\mathrm{t}=37^{\circ} \mathrm{C}$ в атмосфере повышенной влажности и $\mathrm{CO}_{2}$ в течение 24 ч. В качестве специфического стимулятора использовали M. bovis (БЦЖ), предварительно культивированные на среде Левенштейна-Йенсена, в рабочей концентрации 50 мкг / мл. В качестве неспецифического стимулятора применяли КОН А, рабочая концентрация которого составила 25 мкг / мл. Оценку содержания TNF- $\alpha$ в супернатантах культур проводили методом твердофазного иммуноферментного анализа с использованием 2 моноклональных антител в авидинбиотиновой системе (набор реагентов Белорусского НИИ гематологии и переливания крови). Количественный учет результатов реакции оценивали на многоканальном оптическом компараторе "Линкей" (НПО "Научные приборы", Санкт-Петербург). Концентрацию TNF- $\alpha$ (пг / мл) определяли путем построения калибровочной кривой по результатам титрования рекомбинантного TNF- $\alpha$ в качестве стандарта.
Статистическую обработку результатов исследования осуществляли с помощью компьютерных программ Microsoft Excel и Statistica 6.0. Использовали методики описательной статистики (интервал колебаний, медиана, мода) и специальные статистические методики - метод корреляции Спирмена. Оценку достоверности различий величин показателей проводили с использованием непараметрического критерия теста Вилкоксона. В качестве критического уровня достоверности был принят критерий 0,05.

\section{Результаты и обсуждение}

В ходе исследований установлено, что у всех больных саркоидозом уровень спонтанной продукции TNF- $\alpha$ имел большие индивидуальные колебания (от 60 до 8500 пг / мл), медиана $(M e)-250$, мода $(M o)-112$. В целом уровень спонтанной продукции TNF- $\alpha$ у больных саркоидозом был достоверно выше, чем у здоровых (диапазон колебаний у здоровых $0-500$ пг / мл, Me - 112, Mo - 112; $p=0,0043)$. Уровень индуцированной БЦЖ и КОН А продукции TNF- $\alpha$ - достоверно не различался у больных саркоидозом по сравнению со здоровыми. Данные представлены в табл. 1.

Как следует из табл. 1, уровень БЦЖ-индуцированной продукции TNF- $\alpha$ у больных саркоидозом и здоровых также имел большой разброс колебаний, интервал TNF- $\alpha$ у больных саркоидозом составил 200-8 500 пг / мл, Me - 720, Mo - 250, у здоровых 0-4 500 пг / мл, Мe-500, Мо- $112(p=0,1578)$. При изучении индуцированной КОН А продукции ТNF- $\alpha$ выявлена некоторая тенденция к ее повышению в сравнении со здоровыми, но из-за большого размаха колебаний различия недостоверны: так, у больных саркоидозом диапазон колебаний составил

\section{таблииа 1}

Спонтанная и индуцированная антигенами БЦЖ и КОН А продукция TNF- $\alpha$ периферическими мононуклеарными клетками крови у больных саркоидозом и в группе контроля

\begin{tabular}{|c|c|c|c|}
\hline Показатель & $\begin{array}{c}\text { 1-я и 2-я группы, } \\
n=22\end{array}$ & $\begin{array}{c}\text { Группа контроля, } \\
n=15\end{array}$ & $p$ \\
\hline \multicolumn{4}{|c|}{ Спонтанная продукция TNF- $\alpha$, пг / мл } \\
\hline $\begin{array}{l}\text { Диапазон колебаний, } \\
\text { min-max }\end{array}$ & $60-8500$ & $1-500$ & 0,0043 \\
\hline Me & 250 & 112 & \\
\hline Mo & 112 & 112 & \\
\hline \multicolumn{4}{|c|}{ Индуцированная M. bovis (БЦЖ) продукция TNF- $\alpha$, пг / мл } \\
\hline $\begin{array}{l}\text { Диапазон колебаний, } \\
\text { min-max }\end{array}$ & $200-8500$ & $0-4500$ & 0,1578 \\
\hline Me & 720 & 500 & \\
\hline Mo & 250 & 112 & \\
\hline \multicolumn{4}{|c|}{ Индуцированная КОН А продукция TNF- $\alpha$, пг / мл } \\
\hline $\begin{array}{l}\text { Диапазон колебаний, } \\
\text { min-max }\end{array}$ & $300-9360$ & $0-5000$ & 0,0995 \\
\hline Me & 2500 & 700 & \\
\hline Mo & 5000 & 112 & \\
\hline
\end{tabular}

Примечание: min - минимальное значение; max - максимальное значение переменных в вариационном ряду, Ме - медиана, Мо - мода. 
300-9 060 пг / мл (Me - 2 500, Mo - 5 000); у здоровых интервал колебаний - 0-5 000 пг / мл (Me - 700, $M o-112 ; p=0,099)$. Дополнительно было проведено изучение корреляционной зависимости уровня спонтанной продукции TNF- $\alpha$ у больных саркоидозом с некоторыми гематологическими показателями (величиной СОЭ и уровнем лейкоцитов периферической крови) достоверной корреляционной связи не установлено, коэффициент корреляции Спирмена $(r)$ составил $0,09(p=0,67)$ и $0,137(p=0,54)$ соответственно.

Изучалась спонтанная (табл. 2) и индуцированная антигенами БЦЖ и КОН А продукция TNF- $\alpha$ у пациентов с разными клиническими проявлениями саркоидоза (табл. 3).

Как следует из табл. 2, у пациентов с острыми проявлениями саркоидоза (1-я группа) имеется достоверно более высокий уровень спонтанной продукции TNF- $\alpha$ (диапазон колебаний - 250-8 500 пг / мл; $M e-2$ 000; $M o-2$ 500) по сравнению с пациентами 2-й группы (размах колебаний - 60-500 пг / мл; $\left.M e-112 ; M o-112 ; p_{1-2}=0,0093\right)$ и здоровыми лицами (диапазон колебаний - 0-500 пг / мл; Me - 112; Мо - 112; $\left.p_{1-3}=0,0076\right)$.

Аналогичные изменения в сторону увеличения продукции TNF- $\alpha$ у пациентов 1-й группы были получены и при изучении индуцированной продукции M. bovis (БЦЖ). Интервал колебаний индуцирован-

Таблица 2

Спонтанная продукция TNF- $\alpha$ периферическими мононуклеарными клетками крови у больных с разными клиническими проявлениями саркоидоза и в группе контроля

\begin{tabular}{l|c|c|c|c|}
$\begin{array}{c}\text { Продукция } \\
\text { TNF- } \alpha, \text { пг } / \text { мл }\end{array}$ & $\begin{array}{c}1 \text {-я группа, } \\
n=10\end{array}$ & $\begin{array}{c}2-я \text { группа, } \\
n=12\end{array}$ & $\begin{array}{c}\text { Группа конт- } \\
\text { роля, } n=15\end{array}$ & $p$ \\
$\begin{array}{l}\text { Диапазон коле- } \\
\text { баний, min-max }\end{array}$ & $250-8500$ & $60-500$ & $0-500$ & $\begin{array}{l}p_{1-2}=0,0093 ; \\
p_{1-3}=0,0076 ; \\
p_{2-3}=0,8784\end{array}$ \\
Me & 2000 & 112 & 112 & \\
Mo & 2500 & 112 & 112 & \\
\hline
\end{tabular}

Таблица 3 Индуцированная БЦЖ и КОН А продукция TNF- $\alpha$ периферическими мононуклеарными клетками крови у больных с разными клиническими проявлениями саркоидоза и в группе контроля

\begin{tabular}{|c|c|c|c|c|}
\hline Показатели & $\begin{array}{c}1 \text {-я группа, } \\
n=10\end{array}$ & $\begin{array}{c}\text { 2-я группа, } \\
n=12\end{array}$ & $\begin{array}{l}\text { Группа конт- } \\
\text { роля, } n=15\end{array}$ & $p$ \\
\hline \multicolumn{5}{|c|}{ Индуцированная M. bovis (БЦЖ) продукция TNF- $\alpha$, пг / мл } \\
\hline $\begin{array}{l}\text { Диапазон коле- } \\
\text { баний, min-max }\end{array}$ & $200-8500$ & $200-720$ & $0-4500$ & $\begin{array}{l}p_{1-2}=0,0076 \\
p_{1-3}=0,0094 \\
p_{2-3}=0,0114\end{array}$ \\
\hline Me & 1990 & 250 & 500 & \\
\hline Mo & 2500 & 250 & 112 & \\
\hline \multicolumn{5}{|c|}{ Индуцированная КОН А продукция TNF- $\alpha$, пг / мл } \\
\hline $\begin{array}{l}\text { Диапазон коле- } \\
\text { баний, min-max }\end{array}$ & $300-9360$ & $500-5000$ & $0-5000$ & $\begin{array}{l}p_{1-2}=0,1394 ; \\
p_{1-3}=0,034 ; \\
p_{2-3}=0,046\end{array}$ \\
\hline Me & 3750 & 1510 & 700 & \\
\hline Mo & 2500 & 5000 & 112 & \\
\hline
\end{tabular}

ной БЦЖ продукции TNF- $\alpha$ у пациентов 2-й группы составил 200-8 500 пг / мл; Me - 1 990; Mo - 2500 vs 200-720 пг / мл; Me - 250; Мо - 250; у больных 2-й группы $\left(p_{1-2}=0,0076\right)$ и здоровых $(0-4500$ пг / мл; Me - 500; Мo $\left.-112 ; p_{1-3}=0,0413\right)$. Не установлено достоверных различий между уровнем индуцированной КОН А продукции TNF- $\alpha$ у пациентов 1-й группы (размах колебаний - 300-9 360 пг / мл, Мe 3750, Мо - 2 500) в сравнении с пациентами 2-й группы (диапазон колебаний - 500-5 000 пг / мл, $M e-1510, M o-5000 ; p=0,1394)$. Однако в обеих группах уровень индуцированной КОН А продукции был достоверно выше, чем у здоровых (интервал 0-5 000 пг / мл, Мe - 700, Мо - 112; $p_{1-3}=0,0341$, $\left.p_{2-3}=0,0468\right) ;$ см. табл. 3 .

Полученные данные позволяют предполагать, что при саркоидозе в ответ на любое, даже незначительное антигенное раздражение возникает неадекватная пролиферация и активация иммунокомпетентных клеток, что подтверждается гиперпродукцией TNF- $\alpha$ в ответ на неспецифический митоген КОН А, вероятно, приводящая к развитию саркоидного тканевого процесса. Кроме того, результаты исследований подтверждают высказывание других ученых [7] о том, что TNF- $\alpha$ играет важную роль в патогенезе саркоидоза и является своеобразным маркером активности патологического процесса.

\section{Заключение}

Таким образом, у пациентов с саркоидозом наблюдается значительно более выраженная спонтанная (не стимулированная) продукция TNF- $\alpha$ периферическими мононуклеарными клетками крови по сравнению со здоровыми, которая зависит от клинических проявлений заболевания. У пациентов с острым течением саркоидоза с наличием признаков неспецифического воспаления наблюдается достоверно более высокая спонтанная и индуцированная БЦЖ продукция TNF- $\alpha$, превышающая ее уровень у пациентов с бессимптомным течением заболевания и здоровых. Кроме того, гиперпродукция TNF- $\alpha$, индуцированная неспецифическим митогеном КОН А, наблюдается у больных саркоидозом, независимо от клинических признаков активности процесса, в сравнении со здоровыми, что может указывать на повышение функциональной активности иммунокомпетентных клеток у больных саркоидозом и их склонность к гиперреактивности при встрече с антигеном. Эти результаты открывают перспективы медикаментозной коррекции нарушений продукции TNF- $\alpha$ у больных саркоидозом.

\section{Литература}

1. Визель А.А. Саркоидоз: обзор работ последних лет. Пульмонология 2009; 1: 83.

2. Визель А.А., Гурылева М.Э. Саркоидоз. Consilium Меdicum 2002; 4 (4): 202-210.

3. Визель А.А., Амиров Н.Б. Саркоидоз: Учеб.-метод. пособие для слушателей послевузовского и дополнительного 
профессионального образования / Под общ. ред. А.Г.Чучалина, науч. ред. - А.А.Визель, Н.Б.Амиров. Казань: КГМУ; 2010.

4. Визель А.А., Гурылева М.Э., Визель Е.А. и др. Значение фактора некроза опухоли в патогенезе и лечении саркоидоза. Клин. мед. 2003; 9: 4-7.

5. Скрипина А.Г., Визель И.Ю. Фактор некроза опухоли альфа при саркоидозе: от патогенеза к лечению. Вестн. соврем. клин. мед. 2011; 4 (3): 24-28.

6. Терпингорев С.А., Эль Зейн Б.А., Верещагина В.М. и др. Саркоидоз и проблемы его классификации. Вестн. PAMH 2012; 5: 30-37.

7. Gerke A., Hunninghake $G$. The immunology of sarcoidosis. Clin. Chest Med. 2008; 29: 379-390.

8. Baughman R.P., Lower E.E., du Bois R.V. Sarcoidosis. Lancet 2003; 361: 1111-1118.

9. Akio M., Voshiguki S., Tatsuo W. et al. Characteristies of fever and acute-phase response induced in rablits by IL-1 and TNF. Am. J. Physiol. 1989; 256 (1): 35-41.

10. Mrazek F., Holla L.I., Hutyrova B. et al. Association of tumour necrosis factor-alpha, lymphotoxin-alpha and HLADRB1 gene polymorphisms with Lofgrens syndrome in
Chesh patients with sarcoidosis. Tissue Antigens 2005; 65: 163-171.

11. Borissov S., Kupavtzeva E., Bogorodskaia E. Sarcoidosis activity: the approaches comparison. In: Abstract of 7th WASOG congress in Stockholm June 16-19 2002. Stockholm; 2002. Abstr. № 12.

12. Sharma S., Chost B., Sharma S.K. Association of TNF polymorphism with sarcoidosis, its prognosis and tumour necrosis factor $(\mathrm{TNF}-\alpha)$ levels in Asian Indians. Clin. Exp. Immunol. 2008; 151 (2): 251-259.

\section{Информация об авторах}

Салина Татьяна Юрьевна - д. м. н., доцент кафедры фтизиатрии ФПК и ППС ГБОУ ВПО "Саратовский государственный медицинский университет им. В.И.Разумовского" Минздрава России; тел.: (8452) 51 40-65; e-mail: SalinaTU@rambler.ru

Морозова Татьяна Ивановна - д. м. н., проф.; зав. кафедрой фтизиатрии ФПК и ППС ГБОУ ВПО "Саратовский государственный медицинский университет В.И.Разумовского" Минздрава России, главный врач Саратовского областного клинического противотуберкулезного диспансера; тел. / факс: (8452) 26-16-90; e-mail: dispans@san.ru

Поступила 13.05.13 () Салина Т.Ю., Морозова Т.И., 2013 удк 616.24-002.28-092 